\title{
Fertility Protection in Female Oncology Patients: How Should Patients Be Counseled?
}

\author{
Fertilitätsprotektion von onkologischen Patientinnen: \\ Wie sollten die Patientinnen beraten werden?
}

Authors

Affiliations
S. Findeklee ${ }^{1}$, L. Lotz ${ }^{1}$, K. Heusinger ${ }^{1}$, I. Hoffmann ${ }^{2}$, R. Dittrich ${ }^{2}$, M. W. Beckmann ${ }^{1}$

${ }^{1}$ Gynecology and Obstetrics, Universitätsklinikum Erlangen, Erlangen

${ }^{2}$ Gynecologic Endocrinology and Reproductive Medicine, Universitätsklinikum Erlangen, Erlangen
Deutsche Version unter: www.thieme-connect.de/ ejournals/gebfra

$$
\begin{array}{ll}
\text { received } & 21.7 .2015 \\
\text { revised } & 22.8 .2015 \\
\text { accepted } & 25.8 .2015
\end{array}
$$

\section{Bibliography}

DOI http://dx.doi.org/

$10.1055 / \mathrm{s}-0035-1558184$

Geburtsh Frauenheilk 2015; 75 :

1243-1249 ๑ Georg Thieme

Verlag KG Stuttgart · New York . ISSN 0016-5751

\section{Correspondence}

Sebastian Findeklee, Dr. med. Universitätsklinikum Erlangen Gynecology and Obstetrics Universitätsstraße 21-23 91012 Erlangen

sebastian.findeklee@

uk-erlangen.de

\section{Abstract \\ $\nabla$}

Protecting the fertility of patients with oncologic disease is becoming more and more important, as fulfilling the wish to have children is increasingly occurring at a later stage in life and longterm survival rates after cancer are continuing to improve. A number of fertility-preserving options exist. In addition to techniques which have been around for some time such as medical ovarian suppression, ovarian transposition, and organpreserving surgery, there are other, more recent, innovative methods which have developed over the last few years such as cryopreservation of oocytes or ovarian tissue transplantation after completing cancer therapy. As every procedure has its specific advantages and disadvantages, informed patient consent is essential. The physician's aim must be to select the optimal procedure for each patient. The extent of patients' information about the options to preserve fertility in women with oncologic disease remains limited. One of the main reasons for this is that clinicians are not sure how to inform patients about existing procedures and methods. The aim of this review article is to provide help in clinical practice.

\section{Introduction \\ $\nabla$}

In industrialized countries two developments in recent decades have focused the attention of researchers in reproductive medicine on the preservation of fertility.

Socially, there is a trend to postpone having children until later in life, in some cases until the still existing biological limits prevent women from fulfilling their wish to have a child. Between 1993 and 2013 the average age of women in Germany when they gave birth to their first child increased from 25 to 29.3 years [1]. It has long been

\section{Zusammenfassung \\ $\nabla$}

Dem Fertilitätserhalt bei Krebserkrankungen kommt eine immer größere Bedeutung zu, da sich die Erfüllung des Kinderwunschs zunehmend in spätere Lebensphasen verschiebt und das Langzeitüberleben bei Krebs steigt. Es steht eine Vielzahl fertilitätsprotektiver Maßnahmen zur Verfügung. Neben den seit längerer Zeit praktizierten Verfahren der medikamentösen Ovarsuppression, der Transposition der Eierstöcke und der organerhaltenden Chirurgie haben sich in den letzten Jahren die innovativen Methoden Kryokonservierung von Eizellen und Eierstockgewebe mit der späteren Transplantation nach Therapieabschluss etabliert. Jedes Vorgehen hat seine spezifischen Vor- und Nachteile, über die ärztlicherseits aufgeklärt werden muss. Letztendlich geht es darum, für jede Patientin das optimale Verfahren auszuwählen. Immer noch ist die Aufklärungsrate bez. Fertilitätserhalt bei Frauen mit onkologischen Erkrankungen sehr gering. Als wesentlicher Grund hierfür gilt auch, dass bei den Behandelnden eine Unsicherheit darüber besteht, wie sie Patientinnen über Methoden aufklären sollen. Der hier vorgestellte Review-Artikel soll eine Unterstützung im klinischen Alltag bieten.

known that female fertility begins to decline from the age of 30 years ( Fig. 1) [2]. The decreasing number of children born is accompanied by farreaching social changes. At the same time, overall life expectancy still continues to increase. One of the reasons for this is the advances in oncologic therapy which have led to improved long-term survival rates for cancer patients. However, these successes are accompanied by a loss of fertility due to premature ovarian insufficiency triggered by the gonadotoxic side effects of chemotherapy and radiotherapy [3,4]. Many women report that they would still like to have children despite their 


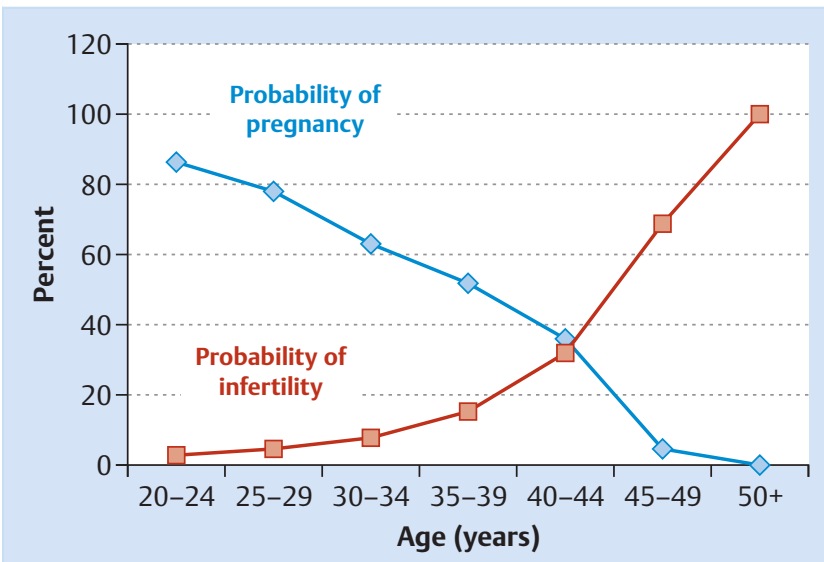

Fig. 1 The decrease of fertility with age (based on H. A. Carcio: Management of the Infertile Woman) [57].

diagnosis of cancer. Every 7th patient would be prepared to accept a reduction in oncologic safety for themselves if as a result they would still be able to have a child [5]. To achieve this, a number of reproductive medicine methods have been developed in recent years and decades. An important distinction in the context of the social changes outlined above is differentiating between non-medical indications (creating a fertility reserve to postpone having a child until a later stage in life, also known as "social freezing") and medical indications (fertility preservation in the context of cancer treatments, primary ovarian insufficiency). If a medical indication is present, the following methods are available: medical ovarian suppression before or during oncologic treatment; surgical techniques such as transposition of the ovaries away from the irradiated area; harvesting and cryopreservation of fertilized or unfertilized oocytes and ovarian tissue. The two last-mentioned methods are also used in women with nonmedical indications. Too few women and men are offered information on fertility-preserving procedures. A new study published in 2015 reported that without special additional training, only $6.7 \%$ of surveyed physicians stated that they initiated a discussion on fertility-preserving procedures with oncology patients. But after receiving the appropriate information, this percentage increased significantly to $46 \%$ [6]. This paper aims to make it easier for treating physicians to talk to female patients about fertility preservation by providing an overview of existing options for fertility preservation, together with a brief description of the prospects of success of the different methods and the impact of treatments on selected tumor entities.

Which chemotherapy regimens, which radiation doses and which other medical tumor therapies are associated with particularly undesirable side effects on the gonads? The important thing here is to be aware that one type of chemotherapy treatment does not equal another. The type and dose of the administered agents determine the toxicity. Cytostatic drugs are associated with increasing fibrosis of the ovaries, leading to a decrease in the number of granulosa cells and primordial follicles [5,7]. Irradiation of brain tissue with more than 35-40 Gy results in most cases in damage to the hypothalamic-pituitary-adrenal axis and hypogonadism [8].

Irradiation of the pelvis promotes fibrosis of the uterus. After irradiation of the ovary with $2 \mathrm{~Gy}$ it is assumed that half of the ov-
Table 1 Risk of gonadal damage after the administration of different cytostatic drugs [10-16]

\begin{tabular}{ll} 
High risk & cyclophosphamide, mitomycin C \\
\hline Intermediate risk & anthracyclines, cisplatin, vinca alkaloids \\
\hline Low risk & methotrexate, 5-fluorouracil \\
\hline Unclear risk & taxanes, gemcitabine
\end{tabular}

ules are destroyed. The threshold dose for damage to the entire ovary is estimated to be $10 \mathrm{~Gy}$ [9].

The most highly gonadotoxic chemotherapeutic drugs are alkylating agents such as cyclophosphamide or platinum derivatives, which are used in gynecology to treat breast cancer, cervical cancer and ovarian cancer. Anthracyclines pose an intermediate risk. Taxanes, which play an important role in the treatment of breast and ovarian cancer, and antimetabolites and vinca alkaloids are associated with the lowest risk of ovarian damage [10]. The chemotherapy-induced amenorrhea rates reported in various clinical studies range from 30-76\%. Amenorrhea was reported in more than $90 \%$ of women after the administration of high-dose chemotherapy $[11,12]$. For cyclophosphamide a clear correlation was demonstrated between age and rate of amenorrhea. The incidence of amenorrhea was found to increase significantly above the age of 35 years, rising to more than $80 \%$ in women aged $>40$ years [13]. In women with Hodgkin's lymphoma treated with cyclophosphamide, van der Kaaij et al. showed that the probability of premature ovarian failure increased by $23 \%$ per year of age [14]. Studies of anthracycline-based chemotherapies administered without the addition of alkylating agents showed that secondary amenorrhea occurred in less than 10 to $34 \%$ of treated women [15]. Pérez-Fidalgo and colleagues noted only a slight and reversible increase in the amenorrhea rate after chemotherapy regimens which included taxanes [16]. - Table 1 provides an overview of the extent of gonadotoxicity of the most common cytostatic drugs used in gynecology and obstetrics.

The data on gonadotoxicity is less clear for the more recent targeted therapies. There are no data on gonadal damage from prospective studies into the leukemia drug imatinib. In a mouse model imatinib had no effect on folliculogenesis or spermatogenesis [17]. It has even been suggested that imatinib could reduce platinum-related gonadotoxicity [8]. However, imatinib use is contraindicated in pregnancy because of the increased risk of congenital malformations. There is also no evidence for trastuzumab-related gonadal damage. A clinical study carried out 5 years ago found no increase in the rate of secondary amenorrhea in breast cancer patients treated with trastuzumab [12]. However, the administration of trastuzumab during pregnancy can result in oligohydramnios, leading to fetal lung hypoplasia and joint contractures [18]. To date no clinical studies have been published on the impact of the anti-VEGF antibody bevacizumab on fertility. There is one case report of two patients treated with bevacizumab for uveal melanoma, who suffered from transient amenorrhea [19]. In 2011 the FDA came out in favor of a warning on the package inserts of the anti-VEGF antibody about the potential undesirable effect on ovarian function. Clinical observations of the drug used to treat intestinal cancer in combination with adjuvant chemotherapy noted a significantly increased risk of amenorrhea, amounting to $34 \%$ in premenopausal women compared with only $2 \%$ of women treated with chemotherapy alone [20]. Nevertheless, the data on the effect of bevacizumab on fertility is still insufficient. The data on the impact on ovarian function of 
the selective estrogen receptor modulator tamoxifen are inconsistent. This is mainly due to the fact that in premenopausal women, tamoxifen treatment usually follows gonadotoxic chemotherapy and radiotherapy. A follow-up study of premenopausal women with breast cancer showed a twofold increased risk of amenorrhea when tamoxifen was added to adjuvant chemotherapy. However, the increased risk was not significant for women who developed breast cancer before the age of 40 years. Moreover, AMH levels were not affected, leading the authors to conclude that tamoxifen only affected follicle development [12].

\section{Overview}

$\nabla$

Protecting fertility in women with cancer: options, safety and success

Organ-preserving surgery

One option to enable women with oncologic disease to have children later on consists of organ-preserving surgery. Cervical conization would therefore be the surgery of choice for women with stage IA cervical cancer, and trachelectomy for women with stage IB cancer of the cervix wishing to have children. It is important, particularly with trachelectomy, to inform the patient about the potential risk of carcinoma recurrence. In the literature, the risk of recurrence is reported to be $11 \%$ after 44 months. Tumor size $>2 \mathrm{~cm}$ and stromal invasion of $>50 \%$ are associated with a higher risk of recurrence [21]. Women opting for trachelectomy must also be informed about the increased risk of miscarriage and premature delivery in any future pregnancy. In a study of 77 pregnant women after fertility-preserving trachelectomy, Hauerberg et al. reported a first trimester miscarriage rate of $21.6 \%$ and a second trimester miscarriage rate of $2.7 \% .12$ of 53 children (23\%) were born prior to $34+0$ weeks of gestation [22]. Organpreserving surgery is the standard procedure to treat borderline ovarian tumors. The 5-year survival rate is reported to be $97 \%$ $[23,24]$. In women with stage I (G1-3) ovarian cancer, preserving the contralateral ovary can be justified. A pregnancy rate of 60$100 \%$ after preservation of one ovary and a miscarriage incidence of less than $30 \%$ is realistic. The risk of disease recurrence is 9$29 \%$ depending on the histology and degree of differentiation; the 5-year survival rate is $83-100 \%$ [25]. In women with higher stage disease the options for organ preservation need to be weighed up very carefully against the significantly increased risk of tumor recurrence. There is almost no data on Fallopian tube carcinomas because of the rarity of the entity. If the tumor is limited to the Fallopian tube, organ preservation of the contralateral side is an option. In up to one third of cases, however, both Fallopian tubes are affected, usually in the ampullary region.

\section{Transposition of the ovaries}

This term describes the surgical transposition of the ovaries away from the area targeted for radiation. With this approach, the ovaries on one or both sides are transposed from the lesser pelvis and, for example, attached proximally to the peritoneum of the abdominal wall. Indications include anal or rectal carcinoma [26]. Patients must be informed about the risks of surgical laparoscopy, although surgical laparoscopy is associated with a low rate of complications. Serious complications such as organ injury or secondary bleeding requiring treatment occur in fewer than $1 \%$ of all laparoscopies $[27,28]$. However, transposition of the ovaries does not protect against the gonadotoxic side effects of chemotherapeutic drugs. One advantage of this method is that ovarian transposition can be carried out together with staging laparoscopy or pelvic lymphadenectomy. Shou et al. reported a success rate of $69.2 \%$ with regard to ovarian preservation [29].

\section{Medical ovarian suppression}

Ovarian suppression before and during gonadotoxic therapy is done using certain GnRH analogs such as goserelin and leuprorelin acetate. They are administered in the form of depot injections for the duration of chemotherapy. The idea is that this downregulates ovarian function with the result that the ovules will react less sensitively to radiotherapy or chemotherapy [30,31]. However, this method cannot be considered the method of choice for fertility preservation as damage to the ovaries including primary ovarian failure can occur despite downregulation [32]. Overall, medical ovarian suppression is not considered to be very effective. Patients need to be informed that primary ovarian failure occurs in up to $60 \%$ of cases despite prophylactic medical downregulation [8]. According to the current ASCO recommendations there is no evidence that medication-based procedures preserve fertility, meaning that such an approach cannot be recommended, at least not on its own, as a method to protect fertility [33].

\section{Cryopreservation of oocytes}

Ovarian stimulation treatment is required to obtain enough oocytes for fertility protection procedures. The principle of treatment consists of hormonal stimulation of the ovaries in accordance with predefined protocols using gonadotropins and suppression of endogenous LH peaks using GnRH analogs such as leuprorelin acetate or GnRH antagonists (e.g. cetrorelix). Follicle puncture for oocyte retrieval is done 36 hours after triggering ovulation. Depending on whether the patient has a long-term male partner, the fertilized or unfertilized ova can be cryopreserved in the pronuclear stage [34]. Careful control is necessary for oocytes to survive the process of cryopreservation. Factors such as oocyte architecture, size and shape affect oocyte survival. Oocytes are cryosensitive due to their high water content. There is a real risk of damaging the oocyte if ice crystals form in the region of the cytoplasm or extracellular matrix. Two methods are used to freeze oocytes, the slow-freezing method and vitrification. In the slow-freezing method the oocyte is slowly frozen in several stages over several hours until reaching $-196^{\circ} \mathrm{C}$. The technique was first established in 1979 by Whittingham [35]. The disadvantages of this method are the length of time and the complex and expensive equipment required for slow freezing [36]. It has since emerged that achieving successful conception is more difficult with this method due to differences in freezing protocols, the use of different cryoprotective culture media and the problem which arises if only a few oocytes can be harvested. A number of different cryoprotective culture media are also used in vitrification, with ethylene glycol and dimethyl sulfoxide the most commonly used media. For vitrification, the oocytes are rapidly cooled to $-196^{\circ} \mathrm{C}$ and stored in liquid nitrogen (also known as shock freezing). Vitrification can be done using either an open system (direct contact between oocytes and liquid nitrogen) or a closed system (oocytes separated from the liquid nitrogen by a membrane) [37]. A systematic review by Edgar et al. compared slow freezing with vitrification and came to the conclusion that vitrification was associated with better oocyte survival and better development of the embryo. The authors were of the opinion that slow freezing of unfertilized oocytes was more likely to result in damage to the oocyte compared to vitrifi- 


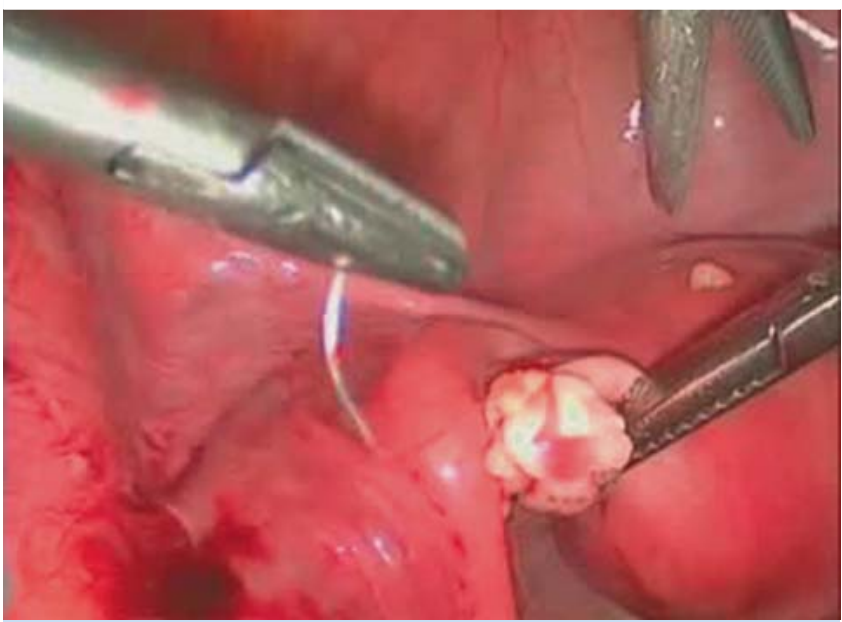

Fig. 2 Orthotopic transplantation into the remaining ovary.

cation. They considered vitrification as the standard procedure for the cryopreservation of oocytes [38]. According to a review by Cobo et al. published in 2009, oocyte survival rates after vitrification were $97 \%$ with an open vitrification system, a significantly higher rate than the $75 \%$ rate obtained with a closed system [39]. According to recent data, the pregnancy rate after transfer of vitrified fertilized oocytes was 38\% [40]. According to Cobo et al., it was even possible to achieve a clinical pregnancy rate of around $60 \%$ for oocytes of equal quality after ovum donation [41]. Conversely, this also means that on average only half of all women who undergo harvesting of oocytes for fertility preservation will become pregnant; this is an issue women need to be informed about in advance.

\section{Cryopreservation of ovarian tissue}

The removal and cryopreservation of ovarian tissue after creating thin tissue sections for slow freezing or vitrification followed by autotransplantation of this tissue has, in recent years, become an established fertility-preserving treatment. After a number of successful animal studies in the 2nd half of the 20th century, the first human birth after transplantation of ovarian tissue was achieved in 2004 [42]. The ovarian tissue used for transplantation can be autologous (tissue is obtained from the patient herself) or allogeneic (tissue is obtained from another patient). Ovarian tissue is transplanted either orthotopically (in the region of the ovary) or heterotopically (at a distance from the ovary, e.g. in the region of the abdominal wall) (๑ Figs. 2 and 3). The amount of ovarian tissue removed depends on the expected extent of loss of ovarian function [43]. Surgical access can be obtained using either laparoscopy or laparotomy. As has occurred in other medical specialties, the minimally-invasive surgical approach has evolved to become the method of choice [44]. Globally, a total of 39 children were born after transplantation of ovarian tissue, although there are still some ongoing pregnancies. There is also data available on 12 births after allogeneic transplantation of fresh ovarian tissue $[45,46]$. Although orthotopic transplantation of ovarian tissue is considered the standard procedure, as the majority of pregnancies and births have been reported with this technique, a report from Australia last year gave an account of a twin birth after heterotopic transplantation of ovarian tissue and IVF. This success could lead to a greater prevalence of heterotopic or simultaneous orthotopic and heterotopic transplantations, as this has the ad-

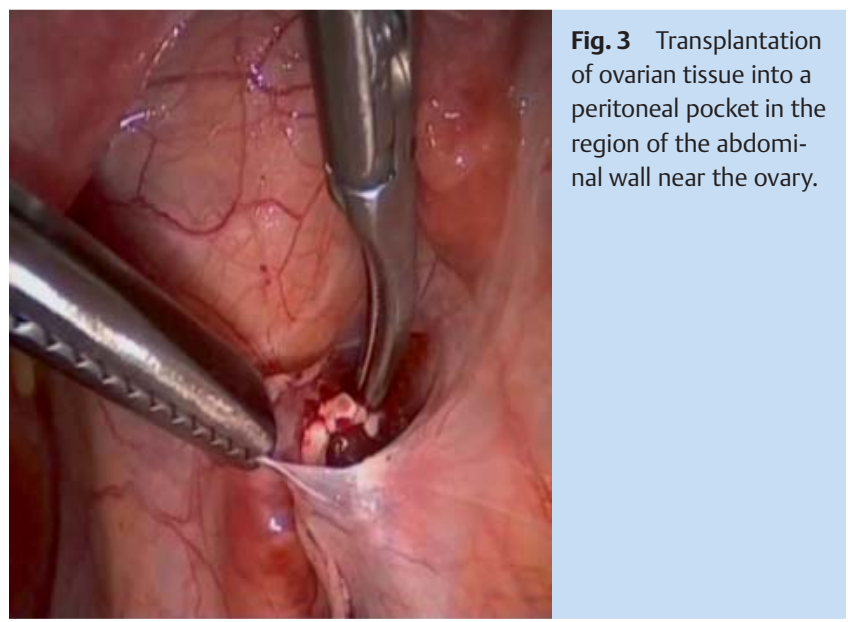

vantage of offering better access for follicle puncture and easier detection of potential tumor recurrence [47].

The decision to cryopreserve oocytes or ovarian tissue must always be taken on an individual basis after close consultation with the patient. The advantage of preserving oocytes is that patients will not have to undergo surgery with its associated risk of potential complications. However, studies have shown that the laparoscopic removal of ovarian tissue followed by its transplantation at a later date is associated with a very low risk of complications of $<1 \%$ [48]. The disadvantages of cryopreserving oocytes are that the number of oocytes obtained may be low, prior hormone treatment may delay the start of oncologic therapy, and there may be potential drug-induced side effects (e.g. ovarian hyperstimulation syndrome). Nowadays, the latter problem can be effectively prevented by optimizing the stimulation protocol, with induction of oocyte maturation through a combined treatment with GnRH analogs and GnRH antagonists [49]. The advantages of cryopreserving ovarian tissue are that oncologic treatment can be started immediately after tissue removal, it is possible to obtain larger numbers of ovules, and spontaneous conception may be possible after successful completion of oncologic treatment, whereas oocyte extraction always requires embryo transfer. It is important to weigh up the stresses for the patient caused by what usually amounts to 2 laparoscopic procedures against the risk of recurrence of disease caused by a potential transplantation of tumor cells. The overall risk of recurrence due to transplantation is low, but it remains a very real risk, particularly with hematologic malignancies [50]. O Table 2 gives an overview of the safety associated with the removal and transplantation of ovarian tissue for different tumor entities. The option to restore fertility and endocrine ovarian function after completing cancer therapy is a clear argument in favor of the cryopreservation of ovarian tissue. If ovarian tissue is not cryopreserved, the patient will often experience premature ovarian failure resulting from the gonadotoxic effects of chemotherapy or radiotherapy. Simple removal of up to $50 \%$ of functional ovarian tissue does not adversely affect ovarian function in the long term, even if the removed ovarian tissue is not re-implanted [51]. The patient must be informed prior to any removal and transplantation of ovarian tissue that generally this method will require at least 2 laparoscopic procedures. According to a recent publication which calculated the pregnancy rates in a total of 80 women after ovarian tis- 
Table 2 Safety of removal and transplantation of ovarian tissue for different tumor entities [37].

\begin{tabular}{llll}
$\begin{array}{l}\text { Tumor entity } \\
\text { Leukemia }\end{array}$ & $\begin{array}{l}\text { Level of evidence } \\
\text { moderate }\end{array}$ & $\begin{array}{l}\text { Strength of recommendation } \\
\text { strong }\end{array}$ & $\begin{array}{l}\text { Risk of tumor cell dissemination } \\
\text { high }\end{array}$ \\
\hline Hodgkin's lymphoma & moderate & strong & low \\
\hline Non-Hodgkin's lymphoma & low & weak & low \\
\hline Breast cancer & moderate & strong & low \\
\hline Sarcoma & low & weak & low \\
\hline Gastrointestinal & low & weak & moderate \\
\hline Gynecological & low & weak & low
\end{tabular}

sue transplantation studied in 4 publications, the likelihood of pregnancy with this method is $25 \%$ [52].

In recent years, increasing numbers of women who wish to preserve fertility for personal reasons have begun to request cryopreservation of oocytes or ovarian tissue. According to an analysis by Nekkebroeck et al., many of these woman are 36-40 years old with above-average levels of education and are often already living with a partner but had not previously had the right partner with whom they wished to have a child. The majority of these women were very satisfied with the procedure, with many of them regretting in hindsight that they had not built up a fertility reserve earlier on $[53,54]$.

- Table 3 summarizes the prospects of success for different fertility protection methods.

\section{Selected tumor entities requiring special information to be provided to patients \\ Hormone receptor-positive breast cancer}

Hormone receptor-positive breast cancer is a special case due to the use of GnRH analogs in treatment. GnRH analogs are administered up to 2 weeks before the start of chemotherapy as well as during chemotherapy. In addition to ovarian suppression, GnRH analogs administered to patients with hormone receptor-positive breast cancer also have an inhibitory effect on tumor cell growth [28]. Patients with hormone receptor-expressing breast cancer should therefore be informed about the benefits of treatment with GnRH analogs and their limited side effects. Removal of ovarian tissue with the option of autotransplantation at a later date can be useful as the risk of transplanting tumor cells appears to be low [55].

\section{Ovarian tumors}

The removal and later transplantation of ovarian tissue in women with malignant ovarian tumors should be considered very critically because of the risk of tumor cell dissemination, although the literature provides no evidence that this will necessarily occur. Lotz et al. analyzed ovarian biopsy samples taken from a total of 23 premenopausal women with epithelial or non-epithelial ovarian malignancies. No malignant cells were detectable under light microscopy or histologically at 24 weeks after xenotransplantation of these ovarian tissue biopsies into severe combined immunodeficient (SCID) mice [56].

\section{Leukemia}

Leukemias are malignancies with the highest risk of tumor dissemination in the ovaries. It is particularly important to inform women with leukemic disease who wish to have children and want to cryopreserve their ovarian tissue of the high risk of implanting tumor cells. According to the literature this risk is highest for patients with chronic myeloid leukemia (CML) [56]. Re-im-
Table 3 Prospects of success for different fertility protection methods [34, 40].

\begin{tabular}{|ll} 
Method & Pregnancy rate \\
\hline Medical suppression & $4-7 \%$ \\
\hline Transposition of the ovaries & $47.5 \%$ \\
\hline Cryopreservation of oocytes & $5 \%$ prospect of implantation per oocyte \\
\hline Cryopreservation of ovarian tissue & $25 \%$ per transplantation \\
\hline
\end{tabular}

plantation of ovarian tissue may not be possible with this tumor entity. Intensive research into new methods to achieve pregnancy without re-implantation of tissue is currently being done, e.g. through in vitro culture of ovarian tissue, but up to now it has not been possible to induce a pregnancy in human females. These patients should opt for cryopreservation of oocytes in addition to cryopreservation of ovarian tissue.

\section{Prospects|Conclusion \\ $\nabla$}

The importance of reproductive medicine for preserving fertility will continue to increase. Developments in the field of in vitro maturation of ovarian tissue may be a viable method in the future which could be used to fulfil the wish of some patients to have a child, particularly those patients for whom the fertility protection method of transplanting ovarian tissue is currently not an option because of the risk of transferring malignant cells together with the re-implanted ovarian tissue. It would not merely offer new perspectives to young women with cancer disease or premature ovarian failure who want to have children, it would also have great potential outside medical indications through the possibility of creating fertility reserves. This is particularly relevant for women who do not have time in their younger years to have children because of extensive professional commitments or do not have children early on because they have not found the right partner. Fertility protection is becoming important not just in the medical setting but also in a social and societal context. A decision tree summarizing the existing options for fertility protection in cancer can be found in $\bullet$ Fig. 4. Future research will focus on many areas, including investigating optimal culture conditions for oocytes or the potential for in vitro maturation of oocytes.

\section{Conflict of Interest \\ $\nabla$}

The authors state that there is no conflict of interest. 


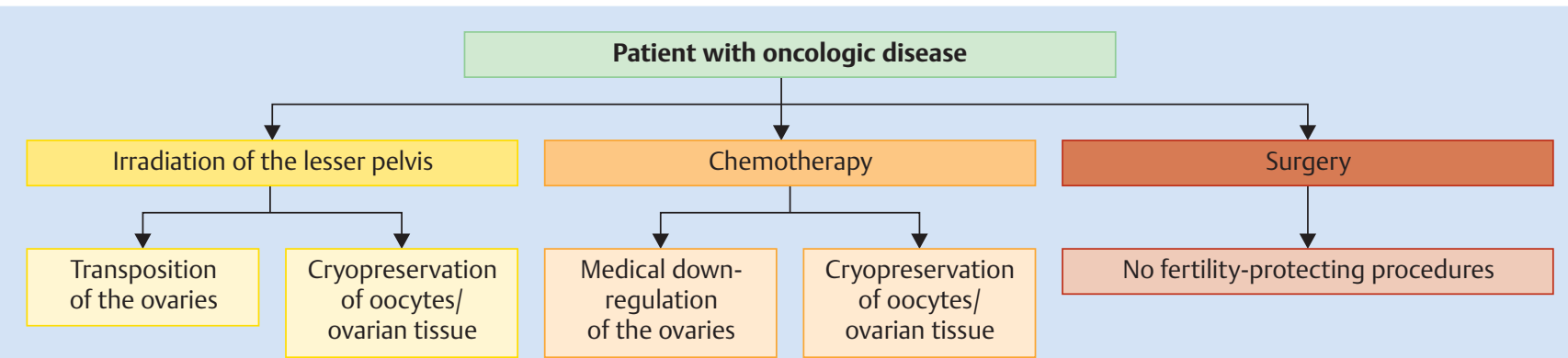

Fig. 4 Decision tree for fertility protection options depending on the oncologic therapy.

\section{References}

1 Statistisches Bundesamt. Alter bei der Geburt des ersten Kinds in Deutschland. Online: https://www.destatis.de/DE/ZahlenFakten/ GesellschaftStaat/Bevoelkerung/Geburten/Tabellen/

GeburtenMutterAlterBundeslaender.html; last access: 30.04.2015

2 Menken J, Trussell J, Larsen U. Age and infertility. Science 1986; 233: 1389-1394

3 Mattle $V$, Behringer $K$, Engert A et al. Female fertility after cytotoxic therapy-protection of ovarian function during chemotherapy of malignant and non-malignant diseases. Eur J Haematol Suppl 2005; 66: 7782

4 Anderson RA, Wallace WH, Baird DT. Ovarian cryopreservation for fertility preservation: indications and outcomes. Reproduction 2008; 136: 681-689

5 Lee MC, Gray J, Han HS et al. Fertility and reproductive considerations in premenopausal patients with breast cancer. Cancer Control 2010; 17: $162-172$

6 Li A, Pasternak M, Duke C et al. The effect of practitioner education on fertility preservation awareness, perception and clinical practice. Obstet Gynecol 2015; 125: 8-9

7 Dnistrian AM, Schwartz MK, Fraccchia AA et al. Endocrine consequences of CMF adjuvant therapy in premenopausal and postmenopausal breast cancer patients. Cancer 1993; 51: 803-807

8 Gonfloni S, Di Tella L, Caldarola S et al. Inhibition of the c-Abl-TAp63 pathway protects mouse oocytes from chemotherapy-induced death. Nat Med 2009; 15: 1179-1185

9 Critchley $\mathrm{HO}$, Wallace WH. Impact of cancer treatment on uterine function. J Nat Can Inst 2005; 34: 64-68

10 Ben-Aharon I, Bar-Joseph H, Tzarfaty G et al. Doxorubicin-induced ovarian toxicity. Reprod Biol Endocrinol 2010; 4: 8-20

11 Hart $R$. Preservation of fertility in adults and children diagnosed with cancer. BMJ 2008; 337: a2045

12 Abusief ME, Missmer SA, Ginsburg ES et al. The effects of paclitaxel, dose density, and trastuzumab on treatment-related amenorrhea in premenopausal women with breast cancer. Cancer 2010; 116: 791-798

13 Parulekar WR, Day AG, Ottaway JA et al.; National Cancer Institute of Canada Clinical Trials Group. Incidence and prognostic impact of amenorrhea during adjuvant therapy in high-risk premenopausal breast cancer: analysis of a National Cancer Institute of Canada Clinical Trials Group Study - NCIC CTG MA. J Clin Oncol 2005; 23: 6002-6008

14 van der Kaaij MA, Heutte N, Meijnders P et al. Premature ovarian failure and fertility in long-term survivors of Hodgkin's lymphoma: a European Organisation for Research and Treatment of Cancer Lymphoma Group and Groupe d'Etude des Lymphomes de l'Adulte Cohort Study. J Clin Oncol 2012; 30: 291-299

15 Elis A, Tevet A, Yerushalmi R et al. Fertility status among women treated for aggressive non-Hodgkin's lymphoma. Leuk Lymphoma 2006; 47: 623-627

16 Pérez-Fidalgo JA, Roselló S, García-Garré E et al. Incidence of chemotherapy-induced amenorrhea in hormone-sensitive breast cancer patients: the impact of addition of taxanes to anthracycline based regimens. Breast Cancer Res Treat 2010; 120: 245-251

17 Schultheis B, Nijmeijer BA, Yin H et al. Imatinib mesylate at therapeutic doses has no impact on folliculogenesis or spermatogenesis in a leukaemic mouse model. Leuk Res 2012; 36: 271-274

18 Witzel ID, Müller V, Harps $E$ et al. Trastuzumab in pregnancy associated with poor fetal outcome. Ann Oncol 2008; 19: 191-192
19 Newman H, Finger PT, Chin KJ et al. Systemic bevacizumab (avastin) for exudative retinal detachment secondary to choroidal melanoma. Eur J Ophthalmol 2011; 21: 796-801

20 Genetech. U.S. BL125085, Supplement. Bevacizumab Genentech, Inc.; 2011

21 ParkJY, Joo WD, Chang SJ et al. Long-term outcomes after fertility-sparing laparoscopic radical trachelectomy in young women with earlystage cervical cancer: an Asan Gynecologic Cancer Group (AGCG) study. J Surg Oncol 2014; 110: 252-257

22 Hauerberg L, Høgdall C, Loft A et al. Vaginal radical trachelectomy for early stage cervical cancer. Results of the Danish National Single Center Strategy. Gynecol Oncol 2015; 138: 304-310

23 Loizzi V, Selvaggi L, Leone L et al. Borderline epithelial tumors of the ovary: experience of 55 patients. Oncol Lett 2015; 9: 912-914

24 Alvarez RM, Vazquez-Vicente D. Fertility sparing treatment in borderline ovarian tumors. Ecancermedicalscience 2015; 9: 507

25 Zapardiel I, Diestro MD, Aletti G. Conservative treatment of early stage ovarian cancer: oncological and fertility outcomes. Eur J Surg Oncol 2014; 40: 387-393

26 Lee SJ, Schover L, Partridge AH et al. American Society of Clinical Oncology recommendations on fertility preservation in cancer patients. J Clin Oncol 2006; 24: 2917-2931

27 Edgar DH, Gook DA. A critical appraisal of cryopreservation (slow cooling versus vitrification) of human oocytes and embryos. Hum Reprod Update 2012; 18: 536-554

28 Morice $P$, Thiam-Ba $R$, Castaigne $\mathrm{D}$ et al. Fertility results after ovarian transposition for pelvic malignancies treated by external irradiation or brachytherapy. Hum Reprod 1998; 13: 660-663

29 Shou $H$, Chen $Y$, Chen $Z$ et al. Laparoscopic ovarian transposition in young women with cervical squamous cell carcinoma treated by primary pelvic irradiation. Eur J Gynaecol Oncol 2015; 36: 25-29

30 Beck-Fruchter $R$, Weiss A, Shalec E. GnRH agonist therapy as ovarian protectants in female patients undergoing chemotherapy: a review of the clinical data. Hum Reprod Update 2008; 14: 553-561

31 Blumenfeld $Z$, von Wolff M. GnRH-analogues and oral contraceptives for fertility preservation in women during chemotherapy. Hum Reprod Update 2008; 14: 543-552

32 Dittrich R, Maltaris T, Hoffmann I et al. Fertility preservation in cancer patients. Minerva Ginecol 2010; 62: 63-80

33 Loren AW, Mangu PB, Beck LN et al. Fertility preservation for patients with cancer: American Society of Clinical Oncology Clinical Practice Guideline Update. J Clin Oncol 2013; 31: 2500-2510

34 Von Wolff $M$, Thaler CJ, Frambach $T$ et al. Ovarian stimulation to cryopreserve fertilized oocytes in cancer patients can be started in the luteal phase. Fertil Steril 2009; 92: 1360-1365

35 Whittingham DG. In-vitro fertilization, embryo transfer and storage. $\mathrm{Br}$ Med Bull 1979; 35: 105-111

36 Sanchez M, Novella-Maestre E, Teruel J et al. The Valencia Programme for Fertility Preservation. Clin Transl Oncol 2008; 10: 433-438

37 Herraiz S, Novella-Maestre E, Rodriguez B et al. Improving ovarian tissue cryopreservation for oncologic patients: slow freezing versus vitrification, effect of different procedures and devices. Fertil Steril 2014; 101: 775-784

38 Cobo A, Vajta G, Remohi J. Vitrification of human mature oocytes in clinical practice. Reprod Biomed Online 2009; 19: 4385 
39 Smith GD, Serafini PC, Fioravanti J et al. Prospective randomized comparison of human oocyte cryopreservation with slow-rate freezing or vitrification. Fertil Steril 2010; 94: 2088-2095

40 Cobo A, Meseguer M, Remohi J et al. Use of cryo-banked oocytes in an ovum donation programme: a prospective, randomized, controlled, clinical trial. Hum Reprod 2010; 25: 2239-2246

41 Donnez J, Dolmans MM, Demylle D et al. Livebirth after orthotopic transplantation of cryopreserved ovarian tissue. Lancet 2004; 364: 1405-1410

42 Oktay K, Karlikaya G. Ovarian function after transplantation of frozen, banked autologous ovarian tissue. N Engl J Med 2000; 342: 1919

43 Krishnakumar S, Tambe P. Laparoscopic entry: a review of techniques, technologies and complications. J Gynecol Endosc Surg 2009; 1: 4-11

44 Donnez J, Dolmans MM, Pellicer A et al. Restoration of ovarian activity and pregnancy after transplantation of cryopreserved ovarian tissue: a review of 60 cases of reimplantation. Fertil Steril 2013; 99: 15031513

45 Donnez J, Dolmans MM. Fertility preservation in women. Nat Rev Endocrinol 2013; 9: 735-749

46 Stern CJ, Gook D, Hale LG et al. Delivery of twins following heterotopic grafting of frozen-thawed ovarian tissue. Hum Reprod 2014; 29: 1828

47 Lawrenz B, Jauckus J, Kupka MS et al. Fertility preservation in $>1,000$ patients: patient's characteristics, spectrum, efficacy and risks of applied preservation techniques. Arch Gynecol Obstet 2011; 283: 651656
48 Corbett S, Shmorgun D, Claman P et al.; Reproductive Endocrinology Infertility Committee. The prevention of ovarian hyperstimulation syndrome. J Obstet Gynaecol Can 2014; 36: 1024-1036

49 Rosendahl M, Andersen MT, Ralfkiaer E et al. Evidence of residual disease in cryopreserved ovarian cortex from female patients with leukaemia. Fertil Steril 2010; 94: 2186-2190

50 Arav A, Gavish Z, Elami A et al. Ovarian function 6 years after cryopreservation and transplantation of whole sheep ovaries. Reprod Biomed Online 2010; 20: 48-52

51 Donnez J, Dolmans MM, Pellicer A et al. Fertility preservation for age-related fertility decline. Lancet 2015; 385: 506-507

52 Nekkebroeck J, Stoop D, Devroey P. O-036 A preliminary profile of women opting for oocyte cryopreservation for non-medical reasons. Hum Reprod 2010; 25: i15-i16

53 Stoop D, Maes E, Polyzos NP et al. Oocyte banking for anticipated gamete exhaustion (AGE) is a preventive intervention, neither social nor nonmedical. Reprod Biomed Online 2014; 28: 548-551

54 Rosendahl M, Greve T, Andersen CY. The safety of transplanting cryopreserved ovarian tissue in cancer patients: a review of the literature. J Assist Reprod Genet 2013; 30: 11-24

55 Lotz L, Montag M, Van der Ven $\mathrm{H}$ et al. Xenotransplantation of cryopreserved ovarian tissue from patients with ovarian tumors into SCID mice-no evidence of malignant cell contamination. Fertil Steril 2011; 95: 2612-2614

56 Rosendahl M, Andersen MT, Ralfkiaer $E$ et al. Evidence of residual disease in cryopreserved ovarian cortex from female patients with leukemia. Fertil Steril 2010; 94: 2186-2190

57 Carcio HA, ed. Management of the infertile Woman. Philadelphia: Lippincott; 1998 